\title{
EVALUATION OF MONOCYTE CHEMOTACTIC PROTEIN (MCP-1) IN SALIVA AS AN EARLY SIGN OF METABOLIC DISORDERS IN PATIENTS WITH CHRONIC KIDNEY DISEASE
}

\author{
Soheir Mohamed Gaafar", Weam AM Rashwan ${ }^{* *}$, Laila Rashed ${ }^{* * *}$ and Eman Magdy Ahmed****
}

\begin{abstract}
Chronic kidney disease incidence have been rising since the publication of the practical guidelines by the Kidney Disease Outcomes Quality Initiation (KDOQI) of the National Kidney Foundation (NKF) in 2002 to reach 200 case per million in many countries around the world with survival rate 3 to 5 years. There are many mechanisms by which chronic kidney disease can affect the oral cavity; uremia, hyperparathyroid hormone, anemia, oxidative stress and and the dramatic rise in inflammatory mediators such as IL-1, IL-6, TNF- $\alpha$, CRP and MCP-1. The oral mucosa, salivary glands, teeth and even periodontal tissues all are affected by the disease. Complications of chronic kidney disease could be prevented if the condition was early detected and controlled; metabolic complications and cardiovascular complication are the most serious complications of chronic kidney disease; both can be early detected and controlled. One successful approach to control the complications is to monitor the inflammatory mediators such as MCP-1a key chemokine; its increasing level translates the decline in renal function and predates the onset of its serious complications.
\end{abstract}

Subjects and methods: The current study was conducted on 50 individuals divided into 4 groups Group 1(15 with a GFR 59-30 ml/min/1.73 m2 "Stage3 CKD"), Group 2 (15 with a GFR 29-15 ml/min/1.73 m2 "Stage 4 CKD"), Group3 (diseased control group, 10 individuals with chronic moderate to severe periodontitis), Group 4: control group, consists of 10 individuals, these patients were selected to be medically free. All groups were subjected to full history, detailed oral examination and salivary sampling.

Results: The salivary MCP-1 values were higher in stage 4 CKD or the late stage $(464 \pm 84.7$ $\mathrm{pg} / \mathrm{ml})$, a relatively decreased salivary flow rate was found in stage 4 CKD which was $(0.8 \pm 0.06$ $\mathrm{ml} / \mathrm{min}$ ). Periodontal disease was higher in stage $4 \mathrm{CKD}$ patients. The gingival index percentage; stage 4 CKD had the significantly higher percentage (95\%), the plaque index results showed that the percentage of teeth surfaces with moderate to severe plaque accumulation was significantly higher in stage 4 CKD (94.9\%), the clinical attachment level results showed that the percentage of surfaces with moderate to severe periodontitis was $(87.6 \%)$, patients in stage 4 had the higher DMFT (24.4 \pm 4.5$)$.

\footnotetext{
* Prof. of Oral Medicine, Oral Diagnosis and Periodontology, Faculty of Oral and Dental Medcine, Cairo University. ** Assis. Prof. of Oral Medicine, Oral Diagnosis and Periodontology, Faculty of Oral and Dental Medcine, Cairo University. *** Prof.of Medical Biochemistry, Faculty of Medcine, Cairo University.

**** Bachelor of Dental Medcine, Faculty of Oral and Dental Medicine,Cairo University.
} 
Conclusion: The MCP-1 values was higher in the salivary samples of patients with chronic kidney disease stage 4 (late stage) than stage 3 (early stage) and the MCP-1 values was higher in both stages compared to both control group. The salivary MCP-1values inversely correlate with the GFR. The dental condition was worsen in chronic kidney disease patients when compared to chronic periodontitis and healthy control groups. A direct proportional relation was found between the DMFT index and the salivary MCP-1 values.

\section{INTRODUCTION}

Good oral health enhances our ability to speak, smile, smell, taste, touch, chew, swallow and convey our feelings through facial expressions. It is therefore an essential part of our everyday lives. According to the World Health Organization, oral health is a state of being free from chronic mouth and facial pain, oral and throat cancer, oral sores, birth defects such as cleft lip and palate, periodontal (gum) disease, tooth decay, tooth loss, and other diseases or disorders that affect the oral cavity. Risk factors for oral diseases include unhealthy diet, tobacco use, harmful alcohol use, and poor oral hygiene (WHO 2011).

The scope of oral medicine focuses on the relation between the patient's oral and systemic condition studying this conflicting relation between different systemic diseases and oral health. Many systemic diseases may affect the oral health and / or dental condition such as diabetes mellitus, blood diseases, liver diseases and lung diseases. Among these systemic diseases is chronic kidney disease (CKD). CKD is a major public health problem threatening many lives around the world (Zhang and Rothenbacher 2008).

Oral diseases may act as a focus of infection giving rise to systemic diseases such as cardiovascular diseases and eye diseases. On the other hand many chronic diseases have oral manifestations, diabetes mellitus for example has many oral manifestations; xerostomia, mucositis and aggravation of the periodontal disease (Enwonwu and Salako 2012). Leukemia is a malignancy in the white blood cells, one of the systemic diseases accompanied by oral manifestations such as oral ulcerations, enlargement of the parotid gland and pulp abscesses (Gowda et al. 2013).

CKD patients may be predisposed to different oral symptoms due to the disease affecting the kidneys, the drugs used for treating the CKD and due to dialysis treatment (López et al. 2006).

Several studies have shown a significantly worse dental health in uremic patients compared to healthy controls regarding the DMFT index (decayed, missing, filled teeth) (Thorman et al. 2009, Ioannidou and Swede in 2011). On the other hand, no significant differences in DMFT index have been found among CKD patients in some studies (Bots et al. 2007, Sobrado et al. 2007). However, most of these studies were done on patients in late stage 4 to 5 or patients with chronic renal failure.

CKD is also associated with worse oral health regarding loss of periodontal attachment, periapical lesions, plaque index, gingival index and calculus surface index (Thorman et al. 2009). However, other studies have shown no differences in dental plaque, gingival bleeding, or periodontal indices in patients with less severe CKD compared to healthy controls (Sobrado et al. 2007, Grubbs et al. 2011).

In a study by Tomás et al. 2008, the whole saliva flow was similar in CKD patients and controls but salivary creatinine, urea, sodium, potassium, chloride and alpha-amylase were significantly higher in end stage renal disease patients (ESRD) patients than controls. Bayraktar et al. 2009 found a salivary flow rate significantly lower in dialysis patients compared to controls. 
ESRD patients have significantly more oral fungal infections than controls and those experiencing mouth dryness and dental plaque formation also seem to be at risk of developing oral fungal infections (Thorman et al. 2009).

Oral candidiasis and diffuse gingival enlargement are increased after renal transplantation mainly as a result of the immunosuppressive therapy or drug side effects. Gingival overgrowth secondary to drug therapy in renal transplant patients has been reported unambiguously and it is mainly associated with cyclosporine, the most commonly used calcineurin inhibitor (Grassi et al. 2006, Al- Mohaya et al. 2009).

The kidney is a bean shaped structure mainly consists of medulla and cortex. The nephron is the functional unit of the kidney, each kidney contains about one million nephron; glomeruli forms the upper part of this nephron that is found into the cortex (figure 1). A process of ultra-filtration of the blood entering the glomeruli through afferent vessel is done and urine is collected into Bowman's space which is cell free, protein free space containing only water with the wastes of the filtration (urine) ready to exit the body (Sobh 2007).

The glomerulus contain 3 cell types; the endothelial cells lining the glomerular capillaries, epithelial cells and mesangial cells which are contractile cells similar to smooth muscle cell and some of them has a macrophage like properties. Filtration occurs along the glomerulus basement membrane (GBM) produced by fusion between the basement membrane of epithelial and endothelial cells. The glomerular capillary's endothelial cells have got pores (Fenestrae) which allow access of the circulatory molecules to the basement membrane on the other side of the basement membrane the glomerular epithelial (podocytes) cells possess multiple long foot which interdegitate with adjacent epithelial cells as well as maintaining the filtration barrier (figure 2), those podocytes are involved in the regulation of filtration and the turnover of the GBM (Goddad et al. 2010).
The filtration barrier of the glomerulus is normally almost absolute to proteins in the size of albumin $(67 \mathrm{~K} \mathrm{Da})$ or larger while proteins of 20 $\mathrm{K}$ Da or smaller filtrate freely. Between those sizes the ability of individual molecule to cross the GBM is influenced by their shape and charge; anionic or negatively charged protein molecules are relatively less freely filtered than cationic ones, little lipid is filtered. The filtration pressure at the GBM is controlled by afferent and efferent arteriolar tone; auto- regulation maintains the constant glomerular filtration rate (GFR) by altering the arteriolar tone over a wide range of systemic blood pressure and renal perfusion pressure. In response to reduction in the perfusion pressure, angiotensine II mediates the constriction of the efferent arterioles which restore the filtration pressure (Goddad et al. 2010).

\section{Aim of the study}

The purpose of the present study is to:

- Evaluate the levels of pro-inflammatory cytokine (MCP-1) a biomarker in secreted stimulated saliva in patients with CKD as an early sign of metabolic disorder for those patients and its relation to their oral condition.

\section{SUBJECTS AND METHODS}

Patients included in this study where retrieved from the chronic kidney disease unit (out patients' clinic) and department of nephrology (inpatients), “Al Kasr Al Aieny" University Hospital. 50patients were examined in this study; patients were categorized into four groups as follow: Group 1(15 with a GFR 59-30 ml/min/1.73 m2 "Stage3 CKD”), Group 2 (15 with a GFR 29-15 ml/min/1.73 m2 "Stage 4 CKD"), Group3 (diseased control group, 10 individuals with chronic moderate to severe periodontitis), Group 4: control group, consists of 10 individuals, these patients were selected to be medically free. For the assessment of the renal function we depended on eGFR for patient categorization and CKD classification. All patients with GFR ranging from $20-60 \mathrm{ml} / \mathrm{min} / 1.73 \mathrm{~m} 2$ not 
showing any of the exclusion criteria were included in group one. All patients with GFR ranging from $15-20 \mathrm{ml} / \mathrm{min} / 1.73 \mathrm{~m} 2$ not showing any of the exclusion criteria were included in group two.The control subjects were selected to be systemically free according to Modified Cornell Medical Index (Brightman, 1994).

All diseased control group suffers from moderate to severe chronic periodontitis. All patients and control group were selected to be age and sex matching. All subjects were informed about the examination routines before examination.

Ethical approval for the study was obtained from the regional ethics committee for human research, Faculty of oral and dental medicine, according to the Cairo University Declaration. The patients were informed orally and a written informed consent to participate was obtained from each subject.

Patients were subjected to full history taking, full clinical examination to oral and dental tissues including examination of the oral mucosa, plaque index, gingival index, and clinical attachment level for evaluation of the periodontal condition and stimulated salivary sample collection for evaluation of MCP-1 and evaluation of the salivary flow rate.

CKD is classified into 5 stages (table1) based on glomerular filtration rate (GFR) to demonstrate the level of kidney function and facilitate the prognosis of the disease in the future.

TABLE (1) Classification of chronic kidney disease (National Kidney Foundation 2002).

\begin{tabular}{|l|l|}
\hline stage & Glomerular filtration rate \\
\hline Stage 1 & $\begin{array}{l}\text { Kidney damage with normal or increased GFR } \geq 90 \\
\mathrm{ml} / \mathrm{min} / 1.73 \mathrm{~m}^{2} .\end{array}$ \\
\hline Stage 2 & $\begin{array}{l}\text { Kidney damage with mild decrease in GFR } 60-90 \\
\mathrm{ml} / \mathrm{min} / 1.73 \mathrm{~m}^{2} .\end{array}$ \\
\hline Stage 3 & $\begin{array}{l}\text { Kidney damage with moderate decrease in GFR } \\
30-59 \quad \mathrm{ml} / \mathrm{min} / 1.73 \mathrm{~m}^{2} .\end{array}$ \\
\hline Stage 4 & $\begin{array}{l}\text { Kidney damage with sever decrease in GFR } 15-29 \\
\mathrm{ml} / \mathrm{min} / 1.73 \mathrm{~m}^{2} .\end{array}$ \\
\hline Stage 5 & Kidney failure GFR $\leq 15 \mathrm{ml} / \mathrm{min} / 1.73 \mathrm{~m}^{2}$ or dialysis \\
\hline
\end{tabular}

\section{RESULTS}

Quantitative data were presented as mean and standard deviation (SD) values. Data were explored for normality using Kolmogorov-Smirnov and Shapiro-Wilk tests. Age, salivary flow rate, MCP-1 levels and CAL data showed parametric distribution while DMFT index and its components, GI and PI data showed non-parametric distribution.

In the present study GFR values were used to describe the decline in renal function in the two CKD stages. MCP-1 values were compared to GFR in different CKD stages in salivary samples; the results showed that salivary MCP-1 values are inversely proportional to the GFR values.

Salivary MCP-1 values were statistically correlated to all other parameters in this study; age, salivary flow, DMFT, GI, PI and CAL. The results have shown that a direct proportional relation was found between MCP-1 and age, M score (number of missing teeth), DMFT, GI, PI, CAL. An inverse proportional relation was found between MCP1 and D score (number of decayed teeth), F score (number of filled teeth) and salivary flow rate.

The results of this study were as follow: The salivary MCP-1 values were higher in stage 4 CKD or the late stage $(464 \pm 84.7 \mathrm{pg} / \mathrm{ml})$, followed by stage 3 CKD or the early stage $(273.5 \pm 42.1 \mathrm{pg} / \mathrm{ml})$, the chronic periodontitis group $(147.5 \pm 20.9 \mathrm{pg} / \mathrm{ml})$ and the healthy control group $(114.3 \pm 8.2 \mathrm{pg} / \mathrm{ml})$.

A relatively decreased salivary flow rate was found in stage $4 \mathrm{CKD}$ which was $(0.8 \pm 0.06 \mathrm{ml} / \mathrm{min})$ and stage $3 \mathrm{CKD}$ which was $(1.4 \pm 0.4 \mathrm{ml} / \mathrm{min})$. The decreased salivary flow rate was significant in both groups compared to the control groups as the chronic periodontitis group was $(1.9 \pm 0.1 \mathrm{ml} / \mathrm{min})$ and the healthy control group was $(2.1 \pm 0.1 \mathrm{ml} / \mathrm{min})$. An inversely proportional relation was found between the salivary flow rate and salivary MCP-1 values

Periodontal disease was higher in stage 4 CKD patients. The gingival index percentage; stage $4 \mathrm{CKD}$ had the significantly higher percentage of surfaces 
with moderate to severe gingival inflammation (95\%), compared to the chronic periodontitis group $(89.5 \%)$, and healthy control group (0\%). Stage 3 CKD was $(82.7 \%)$, the percentage was significantly lower than stage $4 \mathrm{CKD}$ and chronic periodontitis group but was significantly higher than the healthy control group..

The plaque index results showed that the percentage of teeth surfaces with moderate to severe plaque accumulation was significantly higher in stage 4 CKD (94.9\%), compared to the chronic periodontitis group (87.6\%) and the healthy control group $(0 \%)$. Stage 3 CKD was $(86.6 \%)$ the value was significantly lower than stage $4 \mathrm{CKD}$ and not significantly lower than the chronic periodontitis group but was significantly higher than the healthy control group.

The clinical attachment level results showed that the percentage of surfaces with moderate to severe periodontitis was (87.6\%), compared to chronic periodontitis group which was $(81.6 \%)$ and healthy subjects $(0 \%)$ despite the fact that the stage $4 \mathrm{CKD}$ patients had lower number of remaining teeth in relation to all other study groups. Stage 3 was (53.9\%) and it was significantly lower comparing the results to stage $4 \mathrm{CKD}$ and the chronic periodontitis group but was significantly higher than the healthy control group.

TABLE (2) Mean \pm standard deviation (SD) values and results of one-way ANOVA test for comparisons between age values in the four groups.

\begin{tabular}{|c|c|c|c|c|c|}
\hline Age & Group I & Group II & Group III & Group IV & P-value \\
\hline Mean & 46.7 & 54.1 & 52.8 & 46.3 & 0.077 \\
\pm SD & \pm 10.3 & \pm 8.2 & \pm 7.5 & \pm 10.6 & \\
\hline
\end{tabular}

* Significant at $P \leq 0.05$

TABLE (3) Diagnosis of the patients' renal condition according to the primary renal disease as stated by the nephrology departmentuniversity hospital.

\begin{tabular}{|l|l|}
\hline Diagnosis & No. of patients $(\%)$ \\
\hline Glomerulonephritis & $8(26.6 \%)$ \\
\hline Pyelonephritis & $5(16.6 \%)$ \\
\hline Hereditary renal disease & $5(16.6 \%)$ \\
\hline Nephrosclerosis & $12(40 \%)$ \\
\hline
\end{tabular}

TABLE (4) Mean and standard deviation (SD) for the Glomerular filtration rate ( $\mathrm{ml} / \mathrm{min} / 1.73 \mathrm{~m} 2)$ for difference groups tested.

\begin{tabular}{|c|c|c|c|c|c|c|c|c|c|}
\hline & \multicolumn{8}{|c|}{ Group } & \multirow[t]{3}{*}{$\mathrm{p}$-value } \\
\hline & \multicolumn{2}{|c|}{ GP1 } & \multicolumn{2}{|c|}{ GP2 } & \multicolumn{2}{|c|}{ GP3 } & \multicolumn{2}{|c|}{ GP4 } & \\
\hline & Mean & SD & Mean & $\mathrm{SD}$ & Mean & $\mathrm{SD}$ & Mean & $\mathrm{SD}$ & \\
\hline GFR $\left(\mathrm{ml} / \mathrm{min} / 1.73 \mathrm{~m}^{2}\right)$ & $38.78^{\mathrm{b}}$ & 5.92 & $17.08^{c}$ & 1.45 & $90.00^{\mathrm{a}}$ & 0.00 & $90.00^{\mathrm{a}}$ & 0.00 & $\leq 0.001 *$ \\
\hline
\end{tabular}

TABLE (5) Mean \pm standard deviation (SD) values and results of one-way ANOVA and Tukey's tests for comparisons between MCP-1 levels in the four groups.

\begin{tabular}{|c|c|c|c|c|c|}
\hline MCP-1 $(\mathrm{pg} / \mathrm{ml})$ & Group I & Group II & Group III & Group IV & P-value \\
\hline Mean \pm SD & $273.5 \pm 42.1^{\mathrm{b}}$ & $464 \pm 84.7^{\mathrm{a}}$ & $147.5 \pm 20.9^{\mathrm{c}}$ & $114.3 \pm 8.2^{\mathrm{c}}$ & $<0.001^{*}$ \\
\hline
\end{tabular}

*: Significant at $P \leq 0.05$, Means with the same letter within each column are not significantly different at $p=0.05$.Different superscripts are statistically significantly different 
TABLE (6) Percentage of Clinical attachment loss and P value of the Kruskal-Wallis for the difference tested groups.

\begin{tabular}{|c|c|c|c|c|c|c|c|}
\hline & & \multicolumn{3}{|c|}{ Clinical attachment loss } & \multirow{2}{*}{$\begin{array}{c}\text { Moderate to severe } \\
\text { periodontal disease } \%\end{array}$} & \multirow{2}{*}{ Rank } & \multirow{2}{*}{$\mathrm{p}$-value } \\
\hline \multicolumn{2}{|c|}{$1-3$} & $4-5$ & $>6$ & & & & \\
\hline \multirow{4}{*}{ Group } & GP1 & $46.1 \%$ & $35.7 \%$ & $18.2 \%$ & $53.9 \%$ & A & \multirow{4}{*}{$\begin{array}{c}\leq 0.001 \\
*\end{array}$} \\
\hline & GP2 & $12.4 \%$ & $51.2 \%$ & $36.4 \%$ & $87.6 \%$ & B & \\
\hline & GP3 & $18.4 \%$ & $48.4 \%$ & $33.2 \%$ & $81.6 \%$ & D & \\
\hline & GP4 & $100.0 \%$ & $0.0 \%$ & $0.0 \%$ & $0 \%$ & $\mathrm{C}$ & \\
\hline
\end{tabular}

*: Significant at $P \leq 0.05$, Means with the same letter within each column are not significantly different at $p=0.05$.Different superscripts are statistically significantly different

TABLE (7) Results of Spearman's correlation coefficient for the correlation between MCP-1 and different variables.

\begin{tabular}{|l|c|c|}
\hline \multicolumn{1}{|c|}{ Variables } & $\begin{array}{c}\text { Correlation } \\
\text { coefficient }\end{array}$ & P-value \\
\hline MCP-1 and age & 0.336 & $0.017^{*}$ \\
\hline MCP-1 and salivary flow rate & -0.939 & $<0.001^{*}$ \\
\hline MCP-1 and (D) score & -0.433 & $0.002^{*}$ \\
\hline MCP-1 and (M) score & 0.805 & $<0.001^{*}$ \\
\hline MCP-1 and (F) score & -0.801 & $<0.001^{*}$ \\
\hline MCP-1 and DMFT index & 0.471 & $0.001^{*}$ \\
\hline MCP-1 and GI & 0.330 & $0.019 *$ \\
\hline MCP-1 and PI & 0.642 & $<0.001^{*}$ \\
\hline MCP-1 and CAL & -0.908 & $<0.001^{*}$ \\
\hline MCP-1 and GFR & 0.606 & $<0.001^{*}$ \\
\hline
\end{tabular}

\section{*: Significant at $P \leq 0.05$}

\section{DISCUSSION}

The present study was designed to obtain new information about the diagnostic value of salivary MCP-1 expression, oral health and its impact on patients with chronic kidney disease, comparing the results to patients suffering from chronic periodontitis and healthy control subjects.

Many chronic kidney disease (CKD) patients experience uremic symptoms including dry mouth, taste changes, nausea, vomiting and dry retching. Saliva composed of a number of active compounds playing a vital role in taste stimulation. Salivary composition differs in CKD patients and they have an impaired ability to recognize basic tastes. Particularly lower salivary concentrations of bicarbonate are associated with dry mouth and retching, while higher sodium levels and a greater sodium/potassium ratio are associated with nausea. Saliva bicarbonate and urea are associated with taste perception, especially for glutamate and may influence taste function (Manley et al. 2012).

Chronic kidney disease progression could be monitored by many biomarkers found in different body fluids such as blood, urine and saliva. Many studies related the presence of inflammatory markers 
in the urine (Kamijo et al. 2006, Fassett et al. 2011, Nishihara et al. 2013) to the GFR deterioration and progression of kidney function but just one stu

MCP-1 is a pro- inflammatory cytokine that may rise dramatically during progression of CKD and in relation to the GFR declination (Chung and Lan 2011). The MCP-1 is also used as a marker in periodontal disease as it's a highly specific chemoattractant for monocytes and macrophages, these specific types of phagocytic cells which when recruited upon periodontal insult secret a large number of inflammatory mediators that dramatically affect the periodontal structures and the pathogenesis of the periodontal disease (Pradeep et al. 2009). This study was conducted on 50 subjects, 30 of them suffering from chronic kidney disease, at two different stages one early and one late stage in order to compare the MCP-1 values in both stages and correlate the results to the control groups. Patients' grouping was done on biases of GFR test value according to the National Kidney Foundation 2002.

Studies have shown that individuals with chronic periodontal disease have 1.5- 2 fold increased odds of CKD (Fisher et al. 2008). A study by Choi and colleagues in 2012 showed that Aggregatibacter actinomycetemcomitans which is one of the most important pathogens in periodontal disease strongly stimulate the endothelial cells to secret MCP-1.

Ideally, monitoring CKD patients should begin at early stage in order to minimize the acuteness and rapidity of the complications, and to achieve better life (Levey and Coresh 2012). Stage 3 is believed to be the earliest stage in CKD (Crowe 2008).

Stage 4 CKD is the last one before End stage renal disease (ESRD) where renal failure and dialysis or even transplantation takes place (Abboud and Henrich 2011).

Mild Liver Fibrosis from Cirrhosis in Patients Infected with Chronic Hepatitis C Genotype 1.
European J. of Clinical Microbiology \& Infectious Diseases. 2011; 30: 761-766.

Patients with any other systemic and oral condition that can affect the salivary MCP-1values such as: acute infection in the oral cavity (Pradeep et al. 2009), salivary gland disease (Frédéric et al. 2014) and neoplastic lesions (Grivennikov and Karin 2011) were excluded to avoid MCP-1 rise due to infection, the salivary rate changes, oral and periodontal health affection (Durlacher et al. 2010, Morris 2014).

Renal dialysis patients either kept on or only once, renal transplantation or allografts were excluded as metabolic complications already happened way before so it's useless to measure MCP-1 value (Moranne et al. 2009, Thorman et al. 2010).

Patients on antibiotic treatment at time of examination were excluded as antibiotic treatment may reduce the expression of proinflammatory cytokines (Mercer-Jones et al 1998). MercerJones M. A., D. J. Hadjiminas, M. Heinzelmann, J. Peyton, M. Cook and W. G. Cheadle: Continuous antibiotic treatment for experimental abdominal sepsis: effects on organ inflammatory cytokine expression and neutrophil sequestration. British J. of Surgery. 1998; 85(3): 385-389.

Diagnosis of the primary cause of renal disease was stated by the nephrology department, Cairo university hospital in order to avoid diabetes as it's a major cause of renal disease (Couser et al. 2011) but it was clear that diabetes alone may raise the MCP-1 values dramatically (Cha et al. 2012) and worsen the oral and periodontal condition (Daniel et al. 2012) as well as reducing the salivary flow rate (Jawed et al. 2012). Hence all these patients are not enrolled in the current study.

The aim of this study was to evaluate the levels of pro-inflammatory cytokines (MCP-1) a biomarker in secreted stimulated saliva in patients with CKD as an early sign of metabolic disorder for those patients and its relation to their oral condition. 
In the present study every group was subjected to full history taking, full clinical examination of oral and dental tissues; including examination of the oral mucosa, plaque index, gingival index, and clinical attachment level for evaluation of the periodontal condition and stimulated salivary sample collection for evaluation of MCP-1 and the salivary flow rate.

The results of the current study were compared to two control groups each contained 10 patients, one systemically free with chronic periodontitis and one completely healthy (Thorman et al. 2009, Ioannidou and Swede 2011) to correlate the MCP1 values and periodontal condition.

The results of the present study revealed that the age of CKD patients ranged from 28 to 63 years with a mean value $45.5( \pm 17.5)$; CKD may occur at any age. This approaches the average age obtained by Borawski et al. 2007, Grubbs et al. 2012 and Patil et al. 2012. In their studies the mean age was 44 years.

Saliva as a diagnostic fluid may reflect the systemic as well as oral status through a wide spectrum of proteins/ peptides, nucleic acids, electrolytes, and hormones that originate from multiple local and systemic sources and could be found in saliva. The ease of sample collection, handling, storage, and availability of analytical tools at many laboratories were the main causes behind this preference to saliva as a non invasive diagnostic method (Pfaffe et al. 2011).

For all subjects we started by taking salivary samples to avoid contamination of the sample with blood due to oral and periodontal examination, the stimulated salivary sample collection was the most accepted method as these patients may suffer from hypo-salivation (Tomás et al. 2008) also the measurement of resting saliva is difficult to standardize (Larsen et al. 1999) and stimulated saliva is known to vary less throughout the day (Ben-Aryech 1990), however all samples were collected at the same day time 11 am and all patients were given the same instructions not to eat or drink for two hours before to avoid changes in salivary secretion rate as stated by Farnaud et al. 2010.

Spitting method was used as it's a simple way and the foam has a very small volume and expelled air gases won't affect the results (Navazesh and Christensen 1982).

Assessment of the salivary flow rate was done to detect the presence of hyposalivation.

Saliva was immediately delivered and saved at $-80 \mathrm{C}^{0}$ until the Biochemical analysis (Chiappin et al. 2007).

Analysis of the collected salivary samples was performed by means of the enzyme-linked immunosorbent assay (ELISA). ELISA has been considered the standard cytokine measurement method and is widely utilized in clinical laboratories and biomedical research. ELISA kits for commonly measured cytokines are commercially available, cheap and easily used. Additional advantages of ELISA include the fact that results are highly quantitative and generally reproducible (Leng et al. 2008).

Examination of the oral mucosa was carefully done to report any pathological condition in all study groups. The CKD patients may suffer from uremic stomatitis as well as many other oral mucosal lesions either due to the renal disease itself through the dramatic rise in inflammatory mediators and toxic products (Scott and Debbie 2008) or due to the hyposalivation state occurring in CKD (Ariyamuthu et al. 2013).

Another study by Patil et al. in 2012 was conducted on ESRD patients revealed other oral symptoms such as dry mouth, oral ulcers, pallor, altered taste and halitosis as most symptoms are more common in dialysis patients after complete renal failure (Sunil et al. 2012). Those findings weren't present in predialysis patients except halitosis. 
In the present study we used GFR values to describe the decline in renal function in the two CKD stages (Stinghen et al. in 2009, Thorman et al. in 2010, Grubbs et al. in 2012) MCP-1 values where compared to GFR in different CKD stages in salivary samples, the results showed that salivary MCP-1 values are inversely proportional to the GFR values. Salivary MCP-1 values were statistically correlated to all the other parameters in this study, age, salivary flow, DMFT, GI, PI and CAL. It was shown that a direct proportional relation was found between MCP-1 and age, M score (number of missing teeth), DMFT, GI, PI, CAL. An inverse proportional relation was found between MCP1 and D score (number of decayed teeth), F score (number of filled teeth) and salivary flow rate.

The results of the current study showed that salivary MCP-1 values were higher in the late stage of CKD (stage 4 GFR $17.08 \pm 1.45 \mathrm{ml} / \mathrm{min} / 1.73 \mathrm{~m}^{2}$ ) with a mean of $(464 \pm 84.7 \mathrm{pg} / \mathrm{ml})$ values were higher than the early stage (stage 3 GFR $38.78 \pm$ $5.92 \mathrm{ml} / \mathrm{min} / 1.73 \mathrm{~m}^{2}$ ) which came next with a mean of $(273.5 \pm 42.1 \mathrm{pg} / \mathrm{ml})$, the values were also higher than the two control groups; chronic periodontitis group $\left(\mathrm{GFR}=90 \mathrm{ml} / \mathrm{min} / 1.73 \mathrm{~m}^{2}\right)$ with a mean of $(147.5 \pm 20.9 \mathrm{pg} / \mathrm{ml})$ and healthy groups (GFR $=90$ $\left.\mathrm{ml} / \mathrm{min} / 1.73 \mathrm{~m}^{2}\right)$ with a mean of $(114.3 \pm 8.2 \mathrm{pg} / \mathrm{ml})$ and the difference between groups were significant at $\mathrm{P}$ value $\mathrm{P} \leq 0.05$. An inverse correlation was found between the GFR values and salivary MCP-1.

This is in accordance with the results of the study by Camilla et al. 2011 in which the MCP-1 values where compared to GFR in different CKD stages in urinary samples. The study used GFR values to described the decline in renal function in all CKD stages proving that the MCP-1 rising values are essential to the loss of renal function.

The results of the present study approaches these of Stinghen et al. in 2009 who investigated the effects of the uremic diseases on the expression of monocyte chemo-attractant protein-1 (MCP-1) and other inflammatory cytokines and their relation to the cardiovascular complications where GFR was used to determine the renal function of the uremic patients most of them in stage $3 \mathrm{CKD}$, serum MCP-1 was evaluated; the results proved increased MCP-1 values in uremic patients with decreased GFR than control subjects, in which the mean MCP-1 values were $(119.0 \mathrm{pg} / \mathrm{ml})$.

In contrast Thorman et al. in 2010 studied the salivary MCP-1 values together with other inflammatory cytokines in relation to the CKD stage of patients pre- and postdialysis compared to healthy control subjects and found that all cytokines were decreased in CKD patients with MCP-1 mean value of (254 $\mathrm{pg} / \mathrm{ml})$ for the CKD patients and (311 $\mathrm{pg} / \mathrm{ml}$ ) for control subjects. This could be attributed to the different technique the authors used in their study for detection and evaluation of salivary MCP1 values.

Although Murea et al. in 2012 in their study evaluated the MCP-1 in serum in stage $3 \mathrm{CKD}$, their values were in accordance with the values of the salivary MCP-1 in the present study both using the ELISA technique

In a study by Gupta et al. in 2013 the gingival crevicular MCP-1 values were evaluated in patients with severe periodontal disease and compared to healthy control subjects the MCP-1 results were higher in periodontal disease patients. These results were in accordance with the salivary MCP-1 values in the present study.

Also a study by Kusumoto et al. in 2004 proved that the gingival epithelial cell produces MCP-1 after Stimulation with Porphyromonas gingivalis via Toll-Like Receptor 2 in periodontal disease, proving that a higher gingival crevicular fluid (GCF) level of MCP-1 is found in patients with periodontal disease.

Another study by Choi et al. in 2012 investigated the effect of Aggregatibacter 
actinomycetemcomitans on the production of MCP-1 by human umbilical vein endothelial cells (HUVEC). A. actinomycetemcomitans strongly induced the gene expression and protein release of MCP-1 supporting the results of increased MCP-1 in GCF of patients with periodontal disease.

The results of the present study revealed a relatively decreased salivary flow rate in stage 4 CKD (GFR 15-29 ml/min $/ 1.73 \mathrm{~m}^{2}$ ) with a mean value $(0.8 \pm 0.06 \mathrm{ml} / \mathrm{min})$. Stage $3 \mathrm{CKD}(30-59$ $\mathrm{ml} / \mathrm{min} / 1.73 \mathrm{~m}^{2}$ ) patients also showed a decreased salivary flow rate with a mean value $(1.4 \pm 0.4 \mathrm{ml} /$ $\mathrm{min})$. Decreased salivary flow rate was significant in both groups compared to the control groups.

Studies by Thorman et al. in 2010, Vesterinen et al. in 2011 and Ersson et al. in 2011 reported a decreased salivary flow rate in pre-dialysis CKD patients stimulated salivary samples in comparison to healthy control subjects, their results were in accordance with those of the present study.

Studies support the decreased salivary secretion in pre-dialysis CKD patient, but hyposalivation and xerostomia remain evident only in dialysis stages or End stage renal disease (ESRD). Thorman et al. in 2010, Ersson et al. in 2011 and Kaushik et al. in 2013 supported this opinion.

Periodontal screening through gingival and plaque indices as well as clinical attachment loss were carefully determined to evaluate the effect of CKD and its complications on periodontal tissue as assessed by Borawski et al. 2007. Also Thorman et al. 2010 studied the periodontal condition and salivary MCP-1 level in CKD patients.

The results of the present study revealed that the periodontal condition was significantly worse with significantly higher gingival index, plaque index and more clinical attachment loss in CKD patient especially in the advanced group compared to the chronic periodontitis group and the healthy control group.
The results of the present study agree with the study by Bayraktar et al. 2007 in their study they compared the periodontal condition of CKD patients and healthy control subject, although their study was conducted on postdialysis patients, they found a higher gingival and plaque indices but no significant increase in the clinical attachment loss was detected between the two groups.

The results of the present study were in accordance with Almeida et al. in $\mathbf{2 0 1 2}$ who studied the extent and severity of chronic periodontitis in chronic kidney disease (predialysis) stages, the results were compared to healthy individuals and post dialysis patients. Their results revealed a significantly more surfaces with clinical attachment loss in CKD patients pre and postdialysis than control group.

Also in accordance Ioannidou and Swede in 2011 studied the periodontal condition of CKD patients in all stages in relation to healthy individuals and proven a worse periodontal condition in CKD patients than control group.

Borawski et al. 2007 studied pre-dialysis CKD patients in stage $2-5$ and two control groups of generally healthy individuals, one with advanced periodontitis. They reported that periodontal disease was "more severe" in CKD patients compared to healthy individuals which is in accordance to the current study.

On the other hand Grubbs et al. 2011 worked on CKD patients in the United States with eGFR15$59 \mathrm{ml} / \mathrm{min} / 1.73 \mathrm{~m}^{2}$ to evaluate their periodontal condition in relation to control group with chronic periodontitis. The study divided the patients groups according to their educational attainment, their results concluded that association between CKD and chronic periodontitis is not significant among different subpopulations.

DMFT in the present study was recorded to evaluate the oral health of CKD patients and to detect the effect of the disease and its complications on the dental structures as assessed by Thorman et al. 2009. 
The DMFT results of the current study revealed higher $\mathrm{M}$ values (number of missing teeth) in all CKD patients with the highest $M$ value present in stage 4 CKD, stage 3 CKD was next; compared to control groups. The D value (number of decayed teeth) and $\mathrm{F}$ value (number of filled teeth) were higher in the healthy control group.

Collectively CKD patients in stage 4 had the higher DMFT value compared to all other study groups.

The results of the present study agree with Ioannidou and Swede in 2011 who studied the dental and periodontal condition of CKD patients in all stages in relation to healthy individuals and a significantly higher DMFT was found in CKD patients compared to healthy control subjects.

Most patients in this study had untreated dental caries this approaches the results of Vesterinen et al. in 2011 on predialysis patients and healthy control group.

CKD patients had fewer numbers of teeth remaining especially at the late CKD stage, higher number of untreated decayed teeth. This may be illustrated by the lower socioeconomic status of the examined patients and the neglecting to use dental service in CKD. In a study by Grubbs et al. in 2012 on United States patients, it was mentioned that only $11 \%$ of population visit the dentist at least once a year and the percentage is $25 \%$ lower in CKD patients. Patients with CKD are less apt to seek dental service due to the excess appointments and life style changes due to the disease itself. This may affect the dental condition of CKD patients.

The results approach the study by Thorman et al. in 2009 as DMFT was higher in uremic patients than healthy control. However the study didn't mention exactly the CKD stage and it was on both predialysis and post dialysis patients.

On the other hand a study by Sobrado et al. 2007 on patients with moderate to severe CKD comparing the results to healthy control subjects no significant difference was found in DMFT index. However the results of their study reported increased number of missing teeth in CKD patient advanced stages, which were in accordance with the results of the present study.

Bots et al. in 2007 in a longitudinal study on the oral, dental and salivary changes in ESRD patients for two years, no significant difference in DMFT was found between ESRD patients at the beginning of the study which disagrees with the results of the current study. However the values of their results were in accordance with those of the present study at the end of their work.

\section{REFERENCES}

- Abboud H. and Henrich W. M.: Stage 4 chronic kidney disease. The New England J. of Medicine. 2011; 362: 56-65.

- $\quad$ Almeida B. F. S, Figueredo CMS, Bregman R, Suassuna JHR, Fischer RG.: Extent and severity of chronic periodontitis in chronic kidney disease patients. J. of Periodontal Research. 2012; 47: 426-430.

- Al-Mohaya MA, Darwazeh AM, Bin-Salih S, Al-Khudair W.: Oral lesions in Saudi renal transplant patients. Saudi J. of Kidney Diseases \&Transplantation. 2009; 20: 20-29.

- Andersen ES.; Morten Ruhwald; Belinda Moessner; Peer Brehm Christensen; Ove Andersen; Jesper EugenOlsen; Nina Weis: Twelve Potential Fibrosis Markers to Differentiate Mild Liver Fibrosis from Cirrhosis in Patients Infected with Chronic Hepatitis C Genotype 1. European J. of Clinical Microbiology \& Infectious Diseases. 2011; 30: 761-766.

- $\quad$ Ariyamuthu VK., Karl D. Nolph and Bruce E. Ringdahl: Periodontal disease in chronic kidney disease and endstage renal disease patients: a review. J. of Cardio-Renal Medicine. 2013; 3:71-78.

- Bayraktar G, Kurtulus I, Kazancioglu R, Bayramgurler I, Cintan S, Bural C, Bozfakioglu S, Issever H, Yildiz A.: Oral health and inflammation in patients with end-stage renal failure. Peritoneal Dialysis International J. 2009; 29: $472-479$.

- Ben-Aryech H.; Fisher M.; Szargel R. and Laufer D.: Composition of whole unstimulated saliva of healthy children: changes with age. Archieves of Oral Biology J. 1990; 35: 927-930. 
- Borawski et al. 2007 studied pre-dialysis CKD patients in stage $2-5$ and two control groups of generally healthy individuals, one with advanced periodontitis. They reported that periodontal disease was "more severe" in CKD patients compared to healthy individuals which is in accordance to the current study.

- $\quad$ Borawski J, Borawska M, Stokowska W: The periodontal status of predialysis chronic kidney disease and maintenance dialysis patients. Nephrology Dialysis and Transplantation J. 2007; 22: 457-464.

- Borawski J, Borawska M, Stokowska W: The periodontal status of predialysis chronic kidney disease and maintenance dialysis patients. Nephrology Dialysis and Transplantation J. 2007; 22: 457-464.

- $\quad$ Bots C. P., H. S. Brand, J. H. G. Poorterman, B. M. van Amerongen, M. Valentijn-Benz, E. C. I. Veerman, P. M. ter Wee and A. V. Nieuw Amerongen: Oral and salivary changes in patients with end stage renal disease (ESRD): a two year follow-up study. British Dental J. 2007; 207: 47-52.

- $\quad$ Bots C. P., H. S. Brand, J. H. G. Poorterman, B. M. van Amerongen, M. Valentijn-Benz, E. C. I. Veerman, P. M. ter Wee and A. V. Nieuw Amerongen: Oral and salivary changes in patients with end stage renal disease (ESRD): a two year follow-up study. British Dental J. 2007; 207: 47-52.

- Bots et al. in 2007 in a longitudinal study on the oral, dental and salivary changes in ESRD patients for two years, no significant difference in DMFT was found between ESRD patients at the beginning of the study which disagrees with the results of the current study. However the values of their results were in accordance with those of the present study at the end of their work.

- Brightman VJ.: Rational procedures for diagnosis and medical risk assessment. Burket's Oral medicine. Chapter 1. lippinocott Company, Philadelphia. 1994: 729-763.

- Byraktaar G, Kurtulus I, Duraduryan A, Cintan S, Kazanioglu R, Yildiz A, Bural C, Bozfakiglu S, Besler M, Trablus S, Issever H.: Dental and periodontal parameters in hemodialysis patients. J. of Oral Diseases. 2007; 13: 393-397.

- Camilla R., Soumeya Brachemi, Vincent Pichette, Pierre Cartier, Alexandra Laforest-Renald, Tara MacRae, François Madore and Stéphan Troyanov: Urinary monocyte chemotactic protein 1: marker of renal function decline in diabetic and non-diabetic proteinuric renal disease. J. of Nephrology. 2011; 24 (1): 60-67.

- Cha J., Young Youl Hyun, Yi Hwa Jee, Mi Jin Lee, Kum Hyun Han,Young, Sun Kang, Sang Youb Han and Dae Ryong Cha: Plasma leptin concentration are greater in type II diabetes patients and stimulate monocyte chemotactic protein-1 synthesis via the mitogen- activated protein kinase/ extracellular signal- regulated kinase pathway. Kidney Research and Clinical Practice J. 2012; 31:177-185.

- Chiappin S., Giorgia Antonelli, Rosalba Gatti and Elio F. De Palo: Saliva specimen: A new laboratory tool for diagnostic and basic investigation. Clinica Chimica Acta J. 2007; 383: 30-40.

- Choi E.K., Mi-Sun Kang, Byung-Ho Oh, Sang-Yong Kim, So-Hee Kim, and In-Chol Kang: Aggregatibacter actinomycetemcomitans Strongly Stimulates Endothelial Cells to Produce Monocyte Chemoattractant Protein-1 and Interleukin-8. International J. of Oral Biology. 2012; 37(3): 137-145.

- Choi E.K., Mi-Sun Kang, Byung-Ho Oh, Sang-Yong Kim, So-Hee Kim, and In-Chol Kang: Aggregatibacter actinomycetemcomitans Strongly Stimulates Endothelial Cells to Produce Monocyte Chemoattractant Protein-1 and Interleukin-8. International J. of Oral Biology. 2012; 37(3): 137-145.

- Chung A. and Lan H . Y.: Chemokines in renal injury. J. of American Society of Nephrology. 2011; 22: 802-809.

- Couser W. G., Giuseppe Remuzzi, Shanthi Mendis and Marcello Tonelli: The contribution of chronic kidney disease to the global burden of major noncommunicable diseases. International Society of Nephrology J. 2011; 80(12): 1258-1270.

- Crowe E., Halpin D., Stevens P.: Early identification and management of chronic kidney disease, Summary of NICE guidance. British Medical J., 2008; 337: 812-815.

- Daniel R., Subramanium Gokulanathan, Natarajan, Shanmuga Sundaram, Mahalingam Lakshmigandhan, and Thangavelu Kavin: Diabetes and periodontal disease. J. of Pharmacy. 2012; 4(2): 280-282.

- Durlacher J. E., Sharon Elad and Andrei Barasch: Oral mucositis. Oral Oncology J. 2010; 46(6): 452-456.

- $\quad$ Enwonwu C. O. and Salako N.: The periodontal diseasesystemic health-infectious disease axis in developing countries. Periodontology 2000 J. 2012; 60 (1): 64-77. 
- $\quad$ Ersson C., Royne Thorman and Ylva Rodhe: DNA damage in salivary gland tissue in patients with chronic kidney disease, measured by the comet assay. Oral Surgery, Oral Medicine, Oral Pathology, Oral Radiology and Endodontics J. 2011; 112(2): 209-215.

- $\quad$ Farnaud S. J., Ourania Kosti, Stephen J. Getting, and Derek Renshaw: Saliva: Physiology and Diagnostic Potential in Health and Disease. The Scientific World J. 2010; 10: 434-456.

- $\quad$ Fassett R. G., Sree K. Venuthurupalli3, Glenda C. Gobe, Jeff S. Coombes, Matthew A. Cooper and Wendy E. Hoy: Biomarkers in chronic kidney disease: a review. International Society of Nephrology J. 2011; 80: 806-821.

- $\quad$ Fisher MA., George W. T., Brent J. Shelton, Kenneth A. Jamerson, Mahboob Rahman, Akinlolu O. and Ashwini R. Sehgal: Periodontal Disease and Other Nontraditional Risk Factors for CKD. American J. of Kidney Disease. 2008; 51: 45-52.

- $\quad$ Frédéric F., Diana M. Delgado, Philip J. Wexler, Frank G. Oppenheim, Patricia Mitchell, James A. Feldman, David R. Walt et al.: Salivary Inflammatory Mediator Profiling and Correlation to Clinical Disease Markers in Asthma. PLoS ONE J. 2014; 9(1): 844-849.

- Goddad J, A. N. Turner, A. D. Cumming and L. H. Stewart: Davidson's principles and practice of medicine, chapter 17, $21^{\text {th }}$ edition, Elsevier, Phyladelphia. 2010: 473- 581.

- Gowda T.M., Raison T., Shrusi M. S., Garima A. and Dhoom S.M.: Gingival enlargement as an early diagnostic indicator in therapy related acute myeloid leukemia: a rare case report and review of literature. J. of Indian Society of Periodontology. 2013; 17(2): 248-252.

- Grassi FR, Pappalardo S, Baglìo OA, Frateiacci A, Scortichini A, Papa F, De Benedittis M. and Petruzzi M.: Gingival overgrowth in renal transplant recipients induced by pharmacological treatment. Review of the literature. Minerva Stomatology J. 2006; 55: 59-65.

- Grivennikov S. I. and Karin M.: Inflammatory cytokines in cancer: tumour necrosis factor and interleukin 6 take the stage. Annual of Rheumatic Disease. 2011; 70: 104-108.

- Grubbs J., Laura CP., Delphine ST., and Neil RP.: Chronic kidney disease and the use of dental service in a United States public health system: a retrospective cohort study. Biomedical Center of Nephrology J. 2012; 13: 20-28.

- Grubbs J., Laura CP., Delphine ST., and Neil RP.: Chronic kidney disease and the use of dental service in a United
States public health system: a retrospective cohort study. Biomedical Center of Nephrology J. 2012; 13: 20-28.

- Grubbs J., Laura CP., Delphine ST., and Neil RP.: Chronic kidney disease and the use of dental service in a United States public health system: a retrospective cohort study. Biomedical Center of Nephrology J. 2012; 13: 20-28.

- Grubbs J., Laura CP., Delphine ST., and Neil RP.: Chronic kidney disease and the use of dental service in a United States public health system: a retrospective cohort study. Biomedical Center of Nephrology J. 2012; 13: 20-28.

- Grubbs V., Laura C. Plantinga, Deidra C. Crews, Kirsten Bibbins-Domingo, Rajiv Saran, Michael Heung, Priti R. Patel, Nilka Ríos Burrows, Kristina L. Ernst, and Neil R. Powe: Vulnerable Populations and the Association between Periodontal and Chronic Kidney Disease. Clinical J. of American Society of Nephrology. 2011; 6: 711-717.

- Grubbs V., Laura C. Plantinga, Deidra C. Crews, Kirsten Bibbins-Domingo, Rajiv Saran, Michael Heung, Priti R. Patel, Nilka Ríos Burrows, Kristina L. Ernst, and Neil R. Powe: Vulnerable Populations and the Association between Periodontal and Chronic Kidney Disease. Clinical J. of American Society of Nephrology. 2011; 6: 711-717.

- Gupta M, Chaturvedi R, Jain A.: Role of monocyte chemoattractant protein-1 (MCP-1) as an immunediagnostic biomarker in the pathogenesis of chronic periodontal disease. Cytokine J. 2013; 1(3): 892-897.

- Ioannidou E. and Swede H: Disparities in Periodontitis Prevalence among Chronic Kidney Disease Patients. J. of Dental Research. 2011: 90(4); 730-734.

- Ioannidou E. and Swede H: Disparities in Periodontitis Prevalence among Chronic Kidney Disease Patients. J. of Dental Research. 2011: 90(4); 730-734.

- Ioannidou E. and Swede H: Disparities in Periodontitis Prevalence among Chronic Kidney Disease Patients. J. of Dental Research. 2011: 90(4); 730-734.

- Jawed M., Syed M. Shahid, Shah A. Qader and Abid Azhar: Dental caries in diabetes mellitus: role of salivary flow rate and minerals. J. of Diabetes and Its Complications. 2012; 25(3): 183-186.

- Kamijo A. , Takeshi Sugaya, Akihisa Hikawa, Masaya Yamanouchi, Yasunobu Hirata et al.: Urinary liver-type fatty acid binding protein as a useful biomarker in chronic kidney disease. Molecular and Cellular Biochemistry J. 2006; 248:175-182. 
- Kaushik A., S. S. Reddy, L. Umesh, B. K. Y. Devi, N. Santana, and N. Rakesh: Salivary gland changes in renal disease. Indian J. of Nephrology. 2013; 23(2): 125-129.

- KusumotoY.,Hiroyuki Hirano,Keiko Saitoh,Satoru Yamada, Masahide Takedachi et al.: Human Gingival Epithelial Cells Produce Chemotactic Factors Interleukin-8 and Monocyte Chemoattractant Protein-1 After Stimulation With Porphyromonas gingivalis via Toll-Like Receptor 2. J. of Periodontology. 2004; 75(3): 370-379.

- Larsen M.J., Jensen A.F., Madsen D.M. and Pearce E.I.: Individual variations of $\mathrm{pH}$, buffer capacity, and concentrations of calcium and phosphate in unstimulated whole saliva. Archieves of Oral Biology J. 1999: 44; 111-117.

- Leng SX., Janet E. McElhaney, Jeremy D. Walston, Dongxu Xie, Neal S. Fedarko, and George A. Kuchel: ELISA and multiplex technologies for cytokine measurement in inflammation and aging research. J. of Gerontology, Biology Science and Med Science. 2008; 63(8): 879-884.

- $\quad$ Levey A. S. and Coresh J.: Chronic kidney disease. The Lancet J. 2012; 379 (11): 165-180.

- López R. C., Garbero I, Testa MM and Cardenas IL: Isolation of candida species from different niches of oral cavity in periodontal patients, and its relationship with systemic conditions. Biocell J. 2006; 30 (1):196 -200.

- Manley K., Rhivkeh Haryono and Russell Keast: Saliva Composition and Upper Gastro-Intestinal Symptoms in Chronic Kidney Disease. Kidney Research Clinical Practice J. 2012; 31: 156-158.

- Moranne O., Marc Froissart, Jerome Rossert, Cedric Gauci, Jean-Jacques Boffa et al.: Timing of onset of CKDrelated metabolic complications. J. of American Society of Nephrology. 2009; 20: 164-171.

- Morris G. M.: Effects of radiation on the cell proliferation kinetics of epithelial tissues: Therapeutic implications. The British J. of Radiology. 2014; 68 (825): 1259-1285.

- $\quad$ Murea M., Thomas C. Register, Jasmin Divers, Donald W. Bowden, J. Jeffrey Carr et al.: Relationships between serum MCP-1 and subclinical kidney disease: African American-Diabetes Heart Study. Biomedical Center J. 2012; 13: 148- 166 .

- Navazesh M. and Kumar SK.: Measuring salivary flow: Challenges and opportunities. J. of American Dental Association. 2008; 139: 35-40.
- Nishihara K., Satohiro Masuda, Haruka Shinke, Aiko Ozawa, Takaharu Ichimura et al.: Urinary chemokine (C-C motif) ligand 2 (monocyte chemotactic protein-1) as a tubular injury marker for early detection of cisplatininduced nephrotoxicity. Biochemical Pharmacology J. 2013; 85: 570-582.

- Patil S., Suneet Khandelwal, Bharati Doni, Farzan Rahman, Sumita Kaswan: Oral Manifestations in Chronic Renal Failure Patients Attending Two Hospitals in North Karnataka, India. Oral Health and Dental Management J. 2012; 11(3): 100-106.

- Patil S., Suneet Khandelwal, Bharati Doni, Farzan Rahman, Sumita Kaswan: Oral Manifestations in Chronic Renal Failure Patients Attending Two Hospitals in North Karnataka, India. Oral Health and Dental Management J. 2012; 11(3): 100-106.

- $\quad$ Pfaffe T., Justin Cooper White, Peter Beyerlein, Karam Kostner and Chamindie Punyadeera: Diagnostic Potential of saliva: Current state and future applications. Clinical Chemistry J. 2011; 57: 675-687.

- $\quad$ Pradeep A.R.,Happy Daisy, Parag Hadge, Garima Garg, and Manojkumar Thorat: Correlation of Gingival Crevicular Fluid Interleukin-18 and Monocyte Chemoattractant Protein-1 Levels in Periodontal Health and Disease. J. of Periodontology. 2009; 80(9): 1454-1461.

- $\quad$ PradeepA.R.,Happy Daisy, Parag Hadge, Garima Garg, and Manojkumar Thorat: Correlation of Gingival Crevicular Fluid Interleukin-18 and Monocyte Chemoattractant Protein-1 Levels in Periodontal Health and Disease. J. of Periodontology. 2009; 80(9): 1454-1461.

- Scott SD and Debbie LC.: Burket's Oral Medicine. Chapter 15, $11^{\text {th }}$ edition, BC Decker Inc, Philadelphia. 2008: 363-384.

- Sobh A. M.: Essentials of clinical nephrology. Chapter 1, $1^{\text {st }}$ edition. Dar El Shorouk, Egypt. 2007: 21-32.

- Sobrado Marinho JS, Tomás Carmona I, Loureiro A, Limeres Posse J, García Caballero L. and Diz Dios P.: Oral health status in patients with moderate-severe and terminal renal failure. Medicina Oral, Patologia Oral y Cirugi Bucal J. 2007;12: 305-310.

- Sobrado Marinho JS, Tomás Carmona I, Loureiro A, Limeres Posse J, García Caballero L. and Diz Dios P.: Oral health status in patients with moderate-severe and terminal renal failure. Medicina Oral, Patologia Oral y Cirugi Bucal J. 2007;12: 305-310. 
- $\quad$ Stinghen A. E. M., S.M. Gonçalves, E.G. Martines, L.S. Nakao, M.C. Riella C.A. Aita and R. Pecoits-Filho: Increased plasma and endothelial cell expression of chemokines and adhesion molecules in Chronic Kidney Disease. Nephron Clinical Practice J. 2009; 111:117-126.

- $\quad$ Stinghen A. E. M., S.M. Gonçalves, E.G. Martines, L.S. Nakao, M.C. Riella C.A. Aita and R. Pecoits-Filho: Increased plasma and endothelial cell expression of chemokines and adhesion molecules in Chronic Kidney Disease. Nephron Clinical Practice J. 2009; 111:117-126.

- Sunil M. K., Raghav Kumar, Hemant Sawheny, Bosky Guar and Trisha Rastogi: Spectrum or orofacial manifestations in renal disease. J. of Orofacial Research. 2012; 2(4): 216220 .

- Thorman R, Neovius M. and Hylander B.: Clinical findings in oral health during progression of chronic kidney disease to end-stage renal disease in a Swedish population. Scandavian J. of Urology and Nephrology. 2009; 43:154-159.

- Thorman R., Joachim Lundahl, Tülay Yucel-Lindberg and Britta Hylander: Inflammatory cytokines in saliva as an early sign of metabolic disorders in patients with chronic kidney disease. Oral Surgery, Oral Medicine, Oral Pathology, Oral Radiology \& Endodontics J. 2010; 110: 597-604.

- Thorman R., Joachim Lundahl, Tülay Yucel-Lindberg and Britta Hylander: Inflammatory cytokines in saliva as an early sign of metabolic disorders in patients with chronic kidney disease. Oral Surgery, Oral Medicine, Oral Pathology, Oral Radiology \& Endodontics J. 2010; 110: 597-604.

- Thorman R., Joachim Lundahl, Tülay Yucel-Lindberg and Britta Hylander: Inflammatory cytokines in saliva as an early sign of metabolic disorders in patients with chronic kidney disease. Oral Surgery, Oral Medicine, Oral Pathology, Oral Radiology \& Endodontics J. 2010; 110: 597-604.

- Thorman R., Joachim Lundahl, Tülay Yucel-Lindberg and Britta Hylander: Inflammatory cytokines in saliva as an early sign of metabolic disorders in patients with chronic kidney disease. Oral Surgery, Oral Medicine, Oral Pathology, Oral Radiology \& Endodontics J. 2010; 110: 597-604.

- Thorman R., Joachim Lundahl, Tülay Yucel-Lindberg and Britta Hylander: Inflammatory cytokines in saliva as an early sign of metabolic disorders in patients with chronic kidney disease. Oral Surgery, Oral Medicine, Oral Pathology, Oral Radiology \& Endodontics J. 2010; 110: 597-604.

- Tomás I, Marinho JS, Limeres J, Santos MJ, Araújo L and Diz P. Changesin: Salivary composition in patients with renal failure. Archieves of Oral Biology J. 2008; 53:528-532.

- Tomás I, Marinho JS, Limeres J, Santos MJ, Araújo L and Diz P. Changesin: Salivary composition in patients with renal failure. Archieves of Oral Biology J. 2008; 53: 528532 .

- Vesterinen M., Hellevi Ruokonen, Jussi Furuholm, Eero Honkanen and Jukka H. Meurman: Oral health in predialysis patients with emphasis on diabetic nephropathy. Clinical Oral Investigations J. 2011; 15: 99-104.

- World Health Organization (WHO): Policy basis. 2011. On line ref.http://www.who.int/oral_health

- Zhang Q. L. and Rothenbacher D.: Prevalence of Chronic Kidney Disease in population-based studies. J. of Biomedical Center of Public Health. 2008; 8: 117-129. 